\title{
Formation of median nerve by three roots: A case report
}

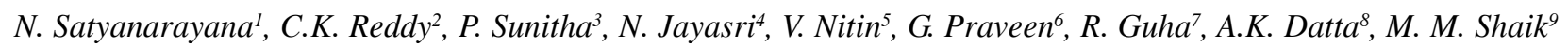

${ }^{1,5,6}$ Lecturer in Anatomy, ${ }^{2}$ Associate Prof in Anatomy, PIMS, Karimnagar, India, ${ }^{3}$ Lecturer in Physiology , ${ }^{7,8}$ Professor in Anatomy, ${ }^{9}$ Lecturer in Pharmacology, College of Medical Sciences, Bharatpur, Nepal, ${ }^{4}$ Professor \& Head, Dept of Anatomy, CAIMS, Karimnagar

\begin{abstract}
:
During routine dissection of an adult male cadaver in the Department of Anatomy, College of Medical Sciences, Bharatpur, Nepal, the right median nerve was found to be formed by three roots. The finding was noted after thorough and meticulous dissection of the upper limbs of both sides (axilla, arm, forearm and palm). Out of the three roots forming the anomalous median nerve, two were from lateral cord and one from medial cord of brachial plexus. However, the distribution of the anomalous median nerve was normal in arm, forearm and palm. The arterial pattern in the arm (axillary and brachial arteries) was also normal.
\end{abstract}

Key words: Cadaver, median nerve, brachial plexus

\section{Case report:}

During routine dissection of an adult male cadaver in the Department of Anatomy, College of Medical Sciences, Bharatpur, Nepal, anomalous median nerve with regard to its formation was found. Dissection of both the upper limbs (axilla, arm, cubital fossa, forearm and palm) was done thoroughly and meticulously to find out the mode of formation, relations and distribution of the anomalous right median nerve and the status of the left median nerve.

It was found that the right median nerve was formed by three roots, two coming from lateral cord and one from medial cord of brachial plexus.

The uppermost or highest root was noted to be at the level of origin of coracobrachialis muscle. The second root was found to be immediately below the first one. These two roots were found to be passing obliquely in Correspondences: Dr. N. Satyanarayana E-mail: satyam_n19@yahoo.com front of second and third part of axillary artery and joining individually with the medial root of median nerve and forming median nerve trunk, in front of third part of axillary artery. (Figure No.-1)

Further distribution of the anomalous median nerve in the arm, forearm and palm was normal. The arterial pattern in arm was also normal. The left median nerve was also normal.

\section{Discussion:}

The median nerve is normally formed by the union of two roots: lateral root of median nerve coming from the lateral cord (C5, C6, C7) of brachial plexus and medial root of median nerve coming from the medial cord $(\mathrm{C} 8, \mathrm{~T} 1)$ of brachial plexus. The two roots embrace the third part of the axillary artery, uniting anterior or lateral to it. Some fibres from C7 often leave the lateral root in the lower part of the axilla passing 
distomedially posterior to the medial root, usually anterior to axillary artery, to join the ulnar nerve: they may branch from the seventh cervical ventral ramus. Clinically they are believed to be mainly motor to the flexor carpi ulnaris.

The median nerve enters the arm at first lateral to the brachial artery. Near the insertion of the coracobrachialis, it crosses in front of (rarely behind) the artery, descending medial to it, to the cubital fossa, where it is posterior to the bicipital aponeurosis and anterior to the brachialis, separated by the latter from the elbow joint. It usually enters the forearm between the heads of the pronator teres, crossing to the lateral side of the ulnar artery and separated from it by the deep head of pronator teres. ${ }^{1}$

Variations in the formation of median nerve were noted by some earlier workers. However, most of the variations as presented by them were related to anomalous relationship between median and musculocutaneous nerves. Chauhan and Roy (2002) reported formation of median nerve by two lateral and one medial root. ${ }^{2}$ Same observation was reported by Saeed and Rufai (2003). ${ }^{3}$

Satyanarayana and Guha (2008) reported formation of median nerve by four roots (three lateral and one medial root). ${ }^{4}$

In other study, it was found that the lateral root was small and the musculocutaneous nerve was connected with median nerve in the arm. ${ }^{5}$

Another study involving dissection of ten cadavers, mentioned failure of separation of musculocutaneous nerve from the median nerve and the latter therefore gave off the branches that should arise from musculocutaneous nerve, namely branches to coracobrachialis, biceps brachii and major part of brachialis. $^{6}$
However the variation related to the formation of median nerve by more than two roots which were observed in the present study is rare as revealed by survey of literatures.

Such variation can be explained in the light of embryogenic development.

The first indication of limb musculature is observed in the seventh week of development as condensation of mesenchyme near the base of the limb buds.

With further elongation of the limb buds, the muscle tissue splits into flexor and extensor compartments.

The upper limb buds lie opposite the lower five cervical and upper two thoracic segments. As soon as the buds form, ventral primary rami from the spinal nerves penetrate into the mesenchyme. At first, each ventral ramus divides into dorsal and ventral branches, but soon these branches unite to form named peripheral nerves which supply extensor and flexor group of muscles respectively.

Immediately after the above mentioned rearrangement of nerves, they enter the limb buds and establish an intimate contact with the differentiating mesodermal condensations and this early contact between the nerve and muscle cells is a prerequisite for their complete functional differentiation. ${ }^{7}$

Over the years, two principal theories have emerged concerning the directional growth of nerve fibres-the neurotropism or chemotropism hypothesis of Ramon y Cajal. ${ }^{8}$ and the principle of contactguidance of Weiss. ${ }^{9}$ The salient feature of chemotropism is that axonal growth cones act as sensors to concentration gradients of molecules in the environment and grow up the gradient towards the source, i.e. the target. 
N. Satyanarayana et al. Unusual case of laryngeal foreign body: A case report

There is no doubt, however that contact guidance mechanisms operate in parallel with neurotropism. Adhesion to the structures with which the growth cone contacts also plays a role.

A group of cell surface receptors viz. neural cell adhesion molecule (N-CAM) and L1 and the Cadherins act as transcription factors which recognize and bind to components of the extracellular matrix. Thus, both cell-cell and cell-matrix interactions may be involved in axonal pathfinding. ${ }^{10}$

Over or under expression of one or multiple transcription factors as mentioned above have been found to be responsible for the variations in the formation, relation and distribution of the motor nerve fibers ${ }^{10}$.

The variations could arise from circulatory factors at the time of fusion of the cords of brachial plexus. ${ }^{11}$

The variations in the formation of median nerve in the arm bear remarkable clinical significance. Considering these variations Rao advocated that the clinicians and surgeons should be aware of such variations while performing surgical procedure in this region. ${ }^{12}$ Injury to such a variant nerve in the proximal arm may lead to a galaxy of manifestations including sensory, motor, vasomotor and trophic changes. ${ }^{3}$

The possible clinical implications of these variations relating either to the surgical approach to the shoulder joint and entrapment syndromes are important. ${ }^{13}$

Anomalies of axillary or brachial artery are frequently related to unusual pattern of brachial plexus and median nerve. ${ }^{14}$ However, in our case no abnormal arterial pattern was detected.

\section{References:}

1. Williams PL, Bannister LH, Berry MM, et al - Gray's Anatomy. In: Nervous System. $38^{\text {th }}$ ed. London Churchill Livingstone, 1999; 1270.
2. Chauhan and Roy Communication between the median and musculocutaneous nerve-a case report.journal of the anatomical Society of India. 2002:52(1):72-5.

3. saeed and Rufai,A.A.-Median nerve and musculocutaneous nerves:variant formation and distribution. Clinical Anatomy.2003:16:453-7.

4. Satyanarayana $N$ and Guha $R$-Formation of median nerve by four roots. J college of medical sciences 2008;vol.5,no.1:105-7.

5. Standring S, Ellis H, Healy JC, et al - Gray's Anatomy. In: General organisation and surface anatomy of the upper limb.39 $9^{\text {th }}$ ed. Philadelphia Elsevier Churchill Livingstone, 2005; 803-4.

6. Guha $R$ and Palit $S$ - A rare variation of anomalous median nerve with absent musculocutaneous nerve and high up division of brachial artery. J Interacad 2005; 9(3): 398-403.

7. Saddler TW - Langman's Medical Embryology. In: Muscular system. 10th ed. Philadelphia Lippincott Williams \& Wilkins, 2006; 146-7.

8. Ramon y Cajal S-Accion neurotropica de los epitelios. Algunos detalles sobre el mecanismo genetico de las ramificaciones nerviosas intraepiteliales sensitivas $y$ sensoriales. Trab Lab Invest Biol 1919; 17:65-8.

9. Weiss $P$ - Nerve patterns: the mechanics of nerve growth. Growth (suppl 5) 1941; 163-203.

10. Williams PL, Bannister LH, Berry MM, et al - Gray's Anatomy. In: Embryology and development. $38^{\text {th }} \mathrm{ed}$. London Churchill Livingstone, 1999; 231-2.

11. Kosugi,K Mortia. T,Yamashita.H: Branching pattern of the musculocutaneous nerve-Jikeakai Medical journal.1986;33:63-71.

12. Rao PPV and Chaudhary SC - Communication of musculocutaneous nerve with the median nerve. East Afr Med J 2000; 77(9):498-503.

13. Venieratos D and Anagnostopoulou S-Classification of communication between musculocutaneous and median nerves. Clin Anat 1998; 11(5): 327-31.

14. Basar R, Aldur MM, Celik HH, et al- A connecting branch between the musculocutaneouos nerve and the median nerve. Morphologie 2000; 84(266): 25-7. 


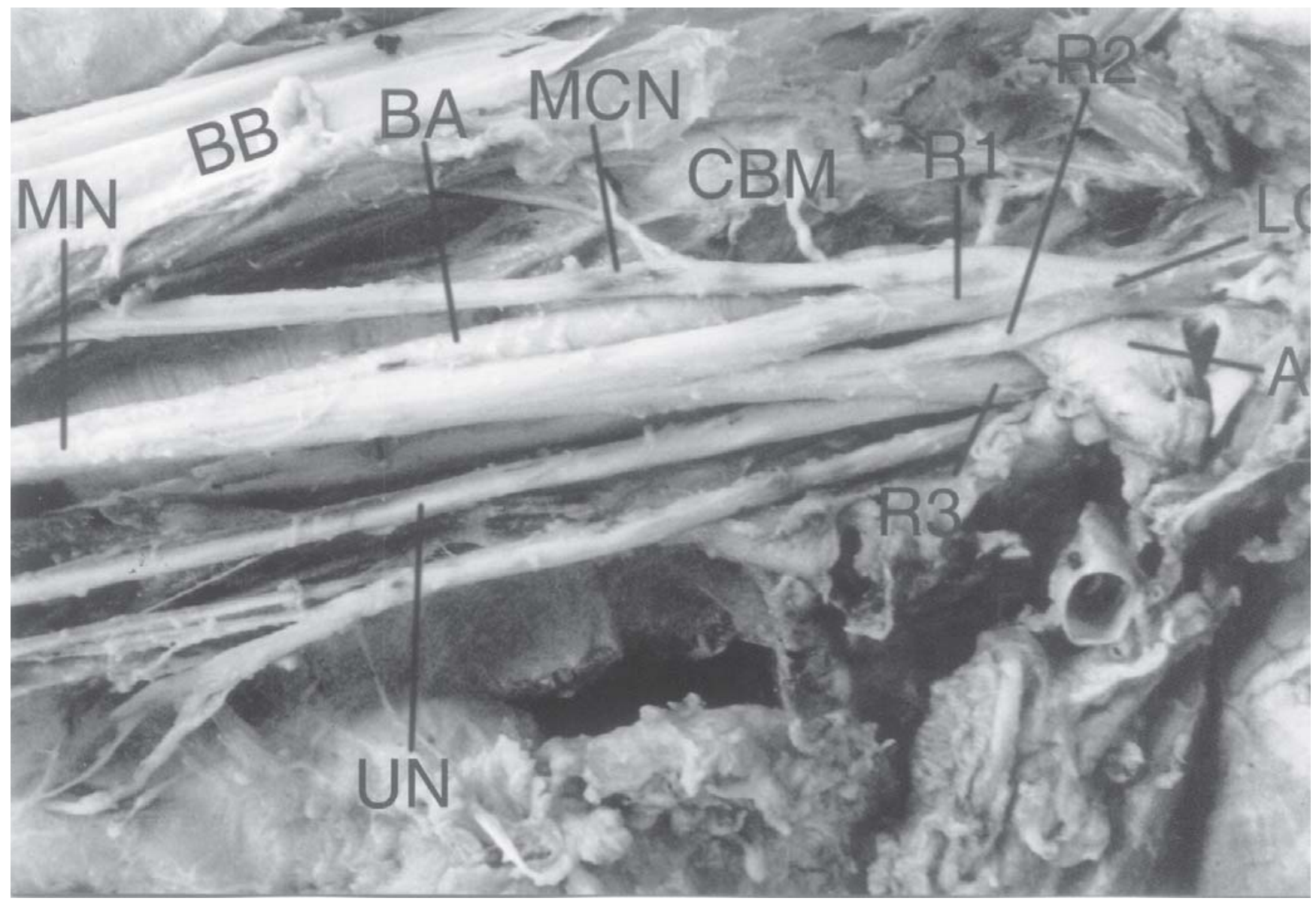

Figure No.-1. Shows formation of median nerve by three roots, two from lateral cord of brachial plexus joining individually with medial root of median nerve forming the median nerve trunk.

$\mathrm{LC}=$ Lateral Cord, $\mathrm{R} 1=$ Root one, $\mathrm{R} 2=$ Root two, $\mathrm{R} 3=$ Root three, $\mathrm{MN}=$ Median nerve, $\mathrm{MCN}=$ Musculocutaneous nerve, $\mathrm{UN}=$ Ulnar nerve, $\mathrm{AA}=$ Axillary artery, $\mathrm{BA}=\mathrm{Brachial}$ artery, $\mathrm{BB}=\mathrm{Biceps}$ Brachii, $\mathrm{CBM}=$ Coracobrachialis Muscle. 